\title{
Pensamiento mágico y espacio urbano en el manga Tokyo Babylon
}

research paper

\section{Magical thinking and urban space in the manga Tokyo Babylon}

\author{
Sarahi Isuki Castelli Olvera ${ }^{1}$ \\ Benemérita Universidad Autónoma de Puebla, México \\ (iD https://orcid.org/0000-0001-5955-6781
}

\author{
Jesús Enciso González² \\ Universidad Autónoma del Estado de Hidalgo, México \\ (iD) https://orcid.org/0000-0002-4806-3268
}

Resumen: En este artículo se analiza, mediante un estudio de caso del manga japonés Tokyo Babylon (1992), cómo el pensamiento mágico está presente en las sociedades contemporáneas y es parte de la vida urbana tanto en países no industrializados como en aquellos que son catalogados del primer mundo. A través de un análisis iconográfico, basado en el paradigma de inferencias indiciales de la microhistoria; concluimos que este manga, creado por el colectivo CLAMP, representa a Tokyo como una ciudad cuyo pensamiento urbano está imbuido por lo mágico a través de la morfología material de la ciudad moderna, surgida del proyecto de renovación de los ochenta y noventa, en la cual tiene continuidad el pensamiento urbano mágico medieval y el samurái. Este trabajo se sustenta en las propuestas de Henry Lefebvre, Henry D. Smith y Pierre Bourdieu.

Palabras clave: magia; Tokyo; manga; urbano; ciudad

\begin{abstract}
This article analyzes, through a case study of the Japanese manga Tokyo Babylon (1992), how magical thinking is present in contemporary societies and is part of urban life in both non-industrialized countries and in those that are considered First world countries. Through an iconographic analysis, based on the paradigm of indexical inferences of microhistory; we conclude that this manga, created by the CLAMP collective, represents Tokyo as a city whose urban thinking is imbued by the magical through the material morphology of the modern city, arising from the renovation project of the ' 80 s and '90s, in which the medieval and samurai magical urban thinking has continuity. This work is based on the proposals of Henry Lefebvre, Henry D. Smith, and Pierre Bourdieu.
\end{abstract}

Keywords: City; Magic; Manga; Tokyo; Urban

\section{Introducción}

La representación de la ciudad en los productos masivos contemporáneos se relaciona con el espacio en el cual se desarrollan las acciones de los actantes a lo largo del relato. El caso del manga y anime no son la excepción y, a través de la gráfica de dichos productos, el espectador de cualquier parte del mundo puede conocer los principales nodos, vías de circulación, hitos y mojones de la ciudad de Tokyo, aún sin haberla visitado

Recibido: 10/09/2020 | Aceptado: 20/01/2021| Disponible en línea: 25/01/2021

Cómo citar: Castelli Olvera, S., y Enciso González, J. (2021). El pensamiento mágico y espacio urbano en el manga Tokyo Babylon. Jangwa Pana, 20(1), 81-100. doi: https://doi.org/10.21676/16574923.3923

\footnotetext{
${ }^{1}$ Correo Electrónico: sarahi.castelli@correo.buap.mx

${ }^{2}$ Correo Electrónico: jesen962@yahoo.com.mx
} 
nunca. En este contexto se desarrollan historias en donde los personajes transitan entre el mundo sagrado y el profano, al tiempo que en sus acciones cotidianas llevan a cabo ritos y prácticas sagradas antiguas, que permiten la pervivencia de la magia, inserta en las acciones diarias de los habitantes urbanos.

Tokyo Babylon es el caso que analizaremos en estas páginas, ya que presenta una historia de corte sobrenatural, en el que la ciudad, convertida en un actante de primera categoría, es el espacio en el que la magia transita y pervive en medio del escenario citadino más moderno y tecnologizado.

\section{La magia en la literatura urbana}

Los fenómenos en los que la magia y el pensamiento mágico se presentan en los espacios citadinos son muy notorios en las novelas, cuentos y cómics de la tradición norte y latinoamericana, europea y oriental, entre otros (Botton, 2003). Se dice que la novela nace con la ciudad, aunque los cuentos tienen raíces mucho más profundas y amarradas con la vida rural (Velasco, 2007). Consideramos que el problema de la magia es planteado abiertamente por la literatura de lo maravilloso, lo fantástico y por el realismo mágico (Nieto, 2015). La forma como lo plantean está en estrecha vinculación con una ciudad capaz de manejar a voluntad a sus habitantes o a los acontecimientos más importantes o nimios de su vida cotidiana (García Cárdenas, 2010). Baste recordar las novelas de Balzac (La piel de zapa), Kafka (El proceso), Dickens (Dos ciudades), Calvino (Ciudades Invisibles), Fuentes (La región más transparente) o Mishima (Confesiones de una máscara), Murakami (Tokio Blues) y Banana Yoshimoto (Tsugumi) para acercarnos un poco a la tradición japonesa. O los impresionantes libros de cuentos de Esquinca y Quirarte (Ciudad fantasma), Borges (El Aleph), Benedetti (La muerte y otras sorpresas), Cortázar (Bestiario), Francisco Tario (La semana escarlata) o Sauce ciego, mujer dormida de Murakami.

Cierta literatura de línea fantástica ha incursionado en cómo el urbanita vive la magia en las ciudades... en cómo la selva asfaltada de símbolos construye o destruye la vida de sus habitantes (Colón y Flores, 2018). Asimismo, en el cómic se ha presentado con demasiada frecuencia el asunto del pensamiento mágico en la vida urbana. Basta recordar algunas icónicas publicaciones como Batman y su ciudad gótica, Superman y su Metrópolis (Bombara, y Valenzuela, 2015) y Fantomas y la elegante vida delictiva europea. Casi todos ellos comics de raigambre. O también podemos considerar las latinoamericanas $L a$ vida en el Limbo de Ahumada, Boogie el aceitoso de Fontanarrosa o la colección de dibujos sin diálogos de Quino Esto no es todo.

Especial mención merecen los cómics y las animaciones japonesas que desde hace tiempo circulan por las librerías mexicanas. En estas publicaciones es común que se trate un especial tipo de tramas donde el manejo energético y mágico es cosa de todos los días en sus personajes. Y es que ciertamente, por razones de su cultura, para los nipones la concepción un individuo capaz de manejar voluntariamente la "energía" puede no ser fantasiosa ni extraordinaria. No hay que olvidar que una mayoría de países asiáticos refieren diversas técnicas que posibilitan dominar la energía interna en el cuerpo humano. Aspectos esenciales de esta filosofía se manifiestan igualmente en tres actividades propias del arte oriental: primero en las más variadas tácticas de relajación y combate de las artes marciales; también en el shönen, la historieta japonesa de aventuras y peleas; y finalmente en mangas como Dragon Ball y en Naruto, entre otros (Bombara, y Valenzuela, 2015). 
Algo muy distinto ocurre con los cómics y animaciones norteamericanas y aquellas que tienen su origen en culturas occidentales. En ellas, el pensamiento mágico siempre se encuentra vertebrado o al menos encubierto por el pensamiento científico. De esta manera, si atendemos a su manufactura, en el cómic norteamericano se intenta revelar las bases científicas de determinado poder. Por el contrario, los japoneses se encaminan a clarificar las técnicas con las que se usa ese poder. Por ejemplo, en el cosmos de Naruto nadie duda de que exista el Ki y los chakras. Otro magnífico ejemplo que surge de los Caballeros del Zodiaco o Saint Seiya es el "séptimo sentido" (Bombara, y Valenzuela, 2015). Es esta creencia tan arraigada de lo mágico en la sociedad japonesa contemporánea y representada por el manga Tokyo Babylon la que vamos a observar en los siguientes apartados.

\section{La magia en las sociedades posmodernas}

Se dice que la posmodernidad inaugura nuevos metarrelatos y que ella misma es un megarrelato (Osorio, 2009). Bajo esta consideración no podemos pensar que la magia en el mundo contemporáneo ha perdido del todo el carácter sobrenatural que tuvo como categoría antropológica en la antigüedad, sino que se le ha dado otro status en las sociedades actuales, por lo que hoy en día la palabra "magia" ha entrado a un lenguaje coloquial y casi mercadológico. En consecuencia, algo ha permanecido de aquellos tiempos primigenios: la magia sigue invocando a las fuerzas naturales y sociales que es donde radica su poderío. Como ya lo mencionaban Hubert y Mauss, citados por Bourdieu (2012):

Si pudiéramos demostrar que en toda la extensión de la magia reinan fuerzas similares a las que actúan en la religión, demostraríamos que la magia tiene el mismo carácter colectivo de la religión. Nada más nos faltaría demostrar cómo esas fuerzas colectivas se produjeron, a pesar del aislamiento de donde nos parecía se encontraban los magos y esto nos conduciría a la idea de que esos individuos no hicieron más que apropiarse de las fuerzas colectivas. (p. 17)

El pensamiento mágico actual se encuentra imbuido en esferas de la vida cotidiana como la mercadotecnia, la medicina, la política, la economía o el urbanismo y, cuando algún problema complejo de estos ámbitos es resuelto de manera satisfactoria, sin conflicto ni violencia, pero desconociendo los verdaderos móviles de la solución, se dice que es obra de magia. Así, el capitalismo, con su tecnología y su ideología, nos ha hecho creer que es capaz de brindar soluciones mágicas, automáticas. Siguiendo a Mauss, diríamos que en realidad lo que han hecho los poderosos del sistema es adueñarse de fuerzas colectivas que brindan una respuesta a los cuestionamientos de la vida urbana. Esta idea de la magia en acción es particularmente visible en los asuntos de orden mercadológico:

Si existe un caso en donde se hagan las cosas con palabras como en la magia, incluso mejor que la magia (si el mago no hace otra cosa que vender con palabras la idea de que hace algo con palabras) es efectivamente en el mundo de la moda. La "firma", simple "palabra pegada al producto" (Elle, 3 de enero de 1972) es sin duda (junto con la firma del pintor consagrado) una de las palabras más potentes económica y simbólicamente que se usan hoy en día. (Bourdieu, 2012, p. 55)

En el capitalismo contemporáneo, la magia entonces está mucho más ligada a la fuerza y a la eficacia de nuevas significaciones sobre el devenir de ciertos contextos sociales que 
a lo sobrenatural en sí mismo. De este modo, y para la mentalidad occidental, toda esta magia no es sino un encubrimiento intencional o no de ciertas circunstancias sociales:

la enumeración positivista de las formas que deben ser respetadas para que se opere la magia de la palabra (el agente correcto, el buen momento, la manera correcta, el lugar correcto, etc.) disimula que el principio de la eficacia de la operación ritual no debe ser buscado en el formalismo mágico (es decir, en el ritual mismo) sino en las condiciones sociales que producen la fe en el ritual y donde el formalismo no es sino un aspecto menor. (Bourdieu, 2012, p. 57)

Estas fuerzas invisibles, pero de alta eficacia, están concentradas en algo que pudiéramos llamar "el capital simbólico". Así, el poder creador y mágico de la moda o del arte, diría Bourdieu (2012), "no es más que la capacidad de movilizar la energía simbólica que produce el conjunto de los agentes comprometidos en el funcionamiento del campo". Ello es así de manera tal que el capitalismo ha generado un gran y eficiente mercado de bienes simbólicos. Al entrar en crisis este mercado, se presenta una disminución de la creencia o la confianza; es decir, han dejado de funcionar los mecanismos que sostienen la fe en determinado bien o bienes simbólicos y dejan de funcionar precisamente porque tales mecanismos ya no salvaguardan los intereses de los agentes fundamentales del sistema de capital de símbolos.

Podemos entonces plantear que lo que está, a fin de cuentas, sosteniendo al pensamiento mágico contemporáneo es el mercado de bienes simbólicos. Dicho pensamiento puede presentarse en circunstancias cotidianas en las que las respuestas normales han dejado de ser eficaces: se requiere por tanto de un conjunto de fuerzas que no están al alcance del individuo medio y que no son fácilmente convocables. Estas fuerzas se ponen en movimiento a través de bienes simbólicos como aquellos que fortalecen o alimentan la memoria, el sentimiento, el estatus, la nostalgia, la esperanza.

\section{La magia y el espacio de la ciudad}

La ciudad, entre las muchas acepciones que tiene, es un bien y una mercancía. Y puede ser entendida también como parte del capital simbólico. Las ciudades tendrían una dimensión muy abstracta como objetos de imaginarios que no son empíricamente vivenciales: simplemente apelan a la memoria, a la nostalgia, al deseo o a un proyecto de vida aún no presente (Carrión, 2005). Así, concebir la ciudad como un símbolo es referirnos a un espacio donde las cosas ocurren "como por arte de magia". Si en el mundo de la alta costura, que es el que estudió Bourdieu, la magia es el poder de una firma o es el mundo ficticio de la publicidad y el periodismo, en la ciudad la magia de lo urbano se refiere no solo a firmas y palabras sino también a la existencia de espacios liminales o fronterizos, donde lo sacro y lo profano es uno solo; a la pervivencia de zonas místicas materializadas en templos y santuarios que con frecuencia ocupan el corazón de los centros históricos. Pero la magia también está en los laboratorios y cubículos de científicos de las universidades, en la bolsa de valores donde la gente se enriquece o se arruina debido a una alquimia social que pueden explicar los economistas especialistas en el capital especulativo, o en las subastas de arte donde objetos nimios pueden alcanzar costos estratosféricos en razón con su procedencia. Magia social es también hablar de la ciudad como el espacio donde transcurrieron los años felices de la niñez, la emoción de la vida del adolescente, la felicidad de los años de matrimonio y paternidad o maternidad, o la vejez, con su fuerte halo de nostalgia por los tiempos idos. En este sentido, la ciudad 
se convierte en un bien simbólico o, más bien, en un conjunto de bienes simbólicos que aportan sentido e identidad al urbanita.

Cosa distinta es ubicarla en su sentido más empírico, ya no como espacio sino como un conjunto de lugares específicos donde se llevan a cabo transacciones y contactos de todo tipo, incluyendo la violencia o la agresión, que a su vez serían causantes de los imaginarios del miedo, de la inseguridad. Es bajo este sentido funcional, sostén de reproducción de comunidades, espacio de relaciones sociales, por el que la ciudad es fundamentalmente un valor de uso (Ornelas, 2015).

En tanto es un sistema de bienes simbólicos, la ciudad echa a andar mecanismos que convocan fuerzas populares o de clases muy altas. Por ejemplo, la nueva oleada de turistificación de las ciudades en todo el mundo, signo de los tiempos actuales cuando la competitividad se ha elevado a valor casi ontológico, ha hecho creer a los habitantes de México que en verdad existen los Pueblos Mágicos tan solo porque el aparato publicitario del gobierno federal así los ha designado. Esta "magia urbana" estaría formada básicamente por la mistificación de una historia local y por el conjunto de instituciones que permiten que la vida del urbanita se desarrolle con ciertos automatismos, a veces con privilegios y a veces con vastas problemáticas que se resuelven por la lógica del dinero y el clientelismo. Son tales instituciones las que, en un primer momento, provocan la alquimia social, el campo en el cual se movilizan las fuerzas colectivas que de manera casi mágica hacen que un ciudadano consiga trabajo, se haga millonario con un sorteo, haga prosperar un negocio, se enriquezca con las redes sociales, consiga una casa, ingrese a una escuela o consiga un título universitario. El bien simbólico de la ciudad está plasmado, entonces, como situaciones o condiciones sociales que se expresan espacial y temporalmente; de ahí que apunte Bourdieu (2012) que la magia es estar en el lugar y en el tiempo preciso para aprovechar lo que da una política pública, un programa, una oferta laboral, una beca o una negociación comercial, entre otras cosas.

Se dice que la ciudad es el espacio de las innovaciones técnicas y sociales, de la "alta cultura", del desarrollo económico y la tecnología de punta ${ }^{3}$, de las macrodecisiones políticas y económicas. Todo esto nos lleva a pensar que es también el lugar donde la magia de lo simbólico puede tener desarrollos más amplios y eficientes. Esto hace que el habitante que está fuera de la ciudad le otorgue a la urbe cualidades de alquimia, en tanto el habitante que está dentro le otorgue cualidades no precisamente mágicas, pero sí superiores. Este fetichismo no es perverso por naturaleza: incluso puede ser una estrategia para darle sentido a una vida demasiado caótica.

De esta manera, encontramos en la ciudad que los habitantes alimentan imaginarios que rescatan aspectos esenciales como el mismo "espacio público" o el "espacio privado". La alquimia social es también la generadora de poderes impersonales, invisibles: por ejemplo, ven al Estado como un monstruo a vencer, un Leviathan, cuando ellos mismos son el Estado, junto con el territorio y el gobierno.

Esta concepción mágica de la ciudad ha sido muy rescatada por los programas turísticos para generar las llamadas ciudades y pueblos marca. Es decir, aquellos donde lo que rige es el imaginario hegemónico construido por la publicidad en tanto actividad donde los

\footnotetext{
${ }^{3}$ Decía Arthur C. Clarke, escritor y científico británico, entre cuyas obras más conocidas se encuentra 2001 : una odisea del espacio, que toda tecnología suficientemente adelantada es indistinguible de la magia.
} 
agentes del campo del turismo se congregan. Aquí lo que se fetichiza o se vuelve ahistórico y estático es el patrimonio, como principal valor a comercializar. Un patrimonio que está plasmado en su arquitectura, en sus habitantes, en su literatura local, en sus narrativas orales o en su historia.

\section{Materiales y métodos}

En este artículo trabajamos bajo el paradigma inductivo de inferencias indiciales, propio de la microhistoria. Este paradigma, creado por Carlo Ginzburg, tiene la característica de enfatizar en la importancia de los detalles, los cuales, durante un análisis, se tienden a dejar de lado por considerarse poco importantes o nimios; sin embargo, suelen portar información amplia relativa a los procesos sociohistóricos, culturales e históricos de la fuente. Desde esta perspectiva, "los datos marginales son considerados reveladores. Así, los detalles que habitualmente se consideran poco importantes, o sencillamente triviales, 'bajos' proporcionan la clave para tener acceso a las más elevadas realizaciones del espíritu humano" (Ginzburg, 1999, p. 143).

Este paradigma y método tiene varias fases principales, como el acercamiento microscópico al fenómeno de estudio, la identificación y descripción de sus detalles, y la relación de estos detalles con su contexto y sus referentes socioculturales e históricos. Esta propuesta se considera fundamental para el análisis de la imagen en la fuente primaria que elegimos, ya que son los detalles presentes en su gráfica y narrativa los que nos permitirán analizar parte de las tradiciones iconográficas representadas, y nos remitirán a elementos más amplios del contexto histórico.

Dicho lo anterior, en este trabajo se examina la fuente tomando como base diálogos e imágenes representativas del manga, las cuales se analizan destacando sus detalles. A partir de ahí, se inicia con la descripción puntual de las imágenes, para posteriormente interpretarlas e insertarlas en su contexto, identificando sus diversos referentes sociohistóricos, religiosos y culturales con las herramientas teóricas desglosadas a lo largo del artículo.

Las imágenes seleccionadas son tres: dos de ellas pertenecen al volumen dos de la edición mexicana, y una al primer volumen; y son pocas porque no son ilustraciones de lo que argumentamos, sino que las consideramos fuente principal del análisis e interpretación. Estas imágenes fueron elegidas porque representan nodos del relato de Tokyo Babylon. La del volumen uno (véase nota al pie número 9) corresponde con la situación inicial de la historia, en la que se presenta la analogía de Tokyo con Babilonia; las otras dos (notas al pie número 5 y 8) corresponden a momentos nodales en la transformación y el final del relato. Al ser imágenes que representan nodos del relato, su composición formal aglomera una serie de elementos visuales y simbólicos representativos sobre el espacio, la ciudad y la magia, los cuales nos permiten una interpretación más puntual de los aspectos simbólicos, sin tener que recorrer todas las imágenes del manga.

\section{Resultados}

\section{La ciudad y el espacio urbano en Tokyo Babylon}

Tokyo Babylon es un manga publicado en Japón por el colectivo CLAMP, el cual está compuesto por cuatro integrantes: Mokona Apapa, Nanase Okawa, Mick Nekoi y Satsuki Igarashi. Se publicó por entregas entre 1990 y 1993 por la editorial Shinshokan dentro de su revista Wings (Pardo, 2012). La versión original japonesa consta de siete tomos recopilatorios. En México, Tokyo Babylon fue publicado en 2016 por Editorial Panini. 
Constó de tres tomos de $15 \mathrm{~cm}$ x $21 \mathrm{~cm}$, portadas e interiores en blanco y negro; incluyó más de 400 páginas por edición ya que cada tomo recopilaba de 2 a 3 tankōbon de la edición original. La elección de esta edición estriba en la importancia que ha tenido la obra de CLAMP en dicho país, en el cual, de manera previa, la ahora extinta Editorial Vid publicó por lo menos diez títulos sin tomar en cuenta el manga que ahora analizamos, el cual llegó a México de manera muy tardía (2017).

Si retomamos la problemática de la alquimia social de la vida urbana, podemos considerar que en este manga se representa a Tokyo como una ciudad cuyo pensamiento urbano se encuentra imbuido por lo mágico a través de la morfología material de la ciudad moderna, surgida del proyecto de renovación de los ochenta y noventa, en la cual tiene continuidad el pensamiento urbano mágico medieval y el samurái. Tokyo Babylon narra la historia de dos clanes, maestros del onmyoudo, quienes trabajan desde tiempos ancestrales de lados opuestos y usando formas contrarias de magia. En la actualidad, sus herederos se encuentran estableciendo una relación que marcará el futuro de manera trágica. ${ }^{4}$

Antes de iniciar el tema de la ciudad y el pensamiento urbano en el manga Tokyo Babylon es necesario dejar en claro algunos de los puntos sobre la manera como se concibe el espacio en este manga: a pesar de que la ciudad es el lugar en el que se desarrollan las acciones, la noción de espacio que se observa en este manga no es solamente lo que Ramírez López (2016) denomina "espacio plano", es decir, "una especie de plataforma donde se ubican objetos, sujetos y fenómenos; una especie de contenedor de materia presente sobre la Tierra"( p. 18). La noción de espacio que se representa en Tokyo Babylon se vincula directamente con los personajes, es su igual, está al mismo nivel: no se trata únicamente del espacio como contenedor, ni del espacio como un reflejo de los pensamientos del personaje, ni siquiera se trata de la noción de espacio que construye al sujeto. En este manga tanto los personajes como el espacio están al mismo nivel, sin contraponerse ni separarse y, por lo tanto, el espacio está construido de dos maneras simultáneas: es un constructo de los actantes, pero también los construye e influye en ellos.

La noción de espacio que trabajamos aquí se relaciona con lo que Emilio García Montiel (1998) denomina $M a$, es decir, "la especial cualidad que la tradición japonesa concede al espacio, al no considerarlo simplemente una zona inerte donde se incluyan las cosas, es un elemento activo o mediador, a través del cual interactúan dos o más objetos” (p. 43). Lo anterior permite entender por qué en este manga el espacio no es plano, sino que tiene un valor que va más allá del escenario.

La noción de $M a$ implica la horizontalidad, que "es tendida según la idea del 'tercero incluido' y que funciona contra la verticalidad o dualismo occidental" (García, 1998, p. 44). Esta noción de ambigüedad es uno de los factores más marcados en Tokyo Babylon y el eje rector sobre el cual se construye la noción de ciudad ya que no hay polarizaciones ni diferencias radicales, por lo tanto, no hay contraposición entre lo natural y lo urbano/humano, ni entre el espacio sagrado y el profano.

a diferencia de los occidentales, los japoneses no conciben al hombre por encima de la naturaleza, sino que la sitúan en el mismo plano, de manera que el hombre, la cultura, lo urbano y lo natural están en un mismo punto, como "un continuum, un

\footnotetext{
${ }^{4}$ Para más detalles de la historia, véase https://www.zonanegativa.com/tokyo-babylon/
} 
todo unitario" (Saito, 2014, p. 3), en donde ninguno es más importante que el otro, y donde uno influye al otro de manera interdependiente. (Castelli, 2017, p. 172)

El Ma y su concepto de horizontalidad brindan al espacio una noción ambigua donde no hay distinción entre el espacio humano y el natural, ni entre lo sagrado y lo profano; de hecho, García Montiel (1998) afirma que los Kami, seres o energías espirituales del shinto, son al mismo tiempo espacio y ser. Igualmente, en Tokyo Babylon los personajes son al mismo tiempo espacio y ser, razón por la que en este artículo dedicamos un importante espacio para hablar de la historia y de las funciones de los personajes en el relato: las personas de la ciudad encarnan Tokyo; sus acciones y representaciones funcionan como una sinécdoque en la que la parte representa al todo. Por ello, las imágenes y las nociones de ciudad y pensamiento urbano que analizaremos a continuación se relacionan íntimamente con los personajes y su interacción con el lugar. Es este artículo, como ya se mencionó con anterioridad, retomamos la idea de Lefebvre (1978), para quien la ciudad es la realidad arquitectónica sensible y lo urbano es la realidad social y el pensamiento vinculado a la ciudad.

En Tokyo Babylon las diferentes concepciones de pensamiento urbano se traslapan: observamos la que deriva del pensamiento mágico antiguo en donde lo sagrado y lo profano son uno. Además de la anterior, se observa a la ciudad como proceso, desde la idea de descomposición y renovación, que va muy de la mano con el pensamiento samurái sobre la ciudad como poder, corrupción y cambio. Cada uno de estos sistemas de pensamiento sobre lo urbano y la ciudad corresponden a un contexto y un momento histórico del país de origen de este manga: Japón.

La primera concepción sobre lo urbano que analizamos es la que se relaciona con lo mágico y la falta de fronteras entre lo mágico y lo humano. Una imagen que condensa lo anterior la conservamos en el volumen dos de la edición mexicana. La escena ocupa dos páginas y, como todo manga, se lee de derecha a izquierda. La página derecha está compuesta por cinco viñetas. Las primeras cuatro se concentran en la parte superior, la última abarca toda la página inferior. La primera viñeta de la parte superior aparece en la esquina derecha y en ella se observa un halcón en pleno vuelo. Bajo esta viñeta hay otra pequeña en la que se representa, en primer plano, parte de las piernas de alguien, se detalla de la rodilla hacia abajo, con traje sastre y de pie en lo que pareciera la cornisa de un edificio. Al fondo, en perspectiva diagonal con un punto de fuga, hay una avenida por la que circulan autos. A los lados de la avenida se observan grandes edificios. Del lado izquierdo de esas dos viñetas hay dos más: la más grande representa parte del rostro y el hombro derecho del sujeto que se encuentra de pie en la cornisa, sobre su hombro se posa el ave; se distingue parte del cabello, la nariz y la boca, pero los ojos no se muestran debido a que sobre ellos se extiende la otra viñeta vertical de aproximadamente un centímetro y medio; en ella se observa, en picada, parte del edificio en el que está parado el hombre. Tras él, sobre el techo del edificio, hay un anuncio espectacular de la marca Sony. En esta misma página, en la parte inferior de la misma, se presenta al sujeto, vestido con un traje negro, los brazos cruzados sobre el pecho y el halcón parado sobre su hombro derecho. Tras él, las letras Sony aparecen en el espectacular.

La página de la izquierda no tiene viñetas como tal, porque la escena la ocupa toda. En esta imagen aparece el sujeto (Seishirou) en Medium Close Up. En su hombro derecho se encuentra posado el halcón, su mano derecha sube hacia el hombro izquierdo al tiempo que sostiene unos lentes cuya terminal izquierda está muy cerca de su boca. Seishirou 
sonríe. ${ }^{5}$ La escena anteriormente descrita representa a Seishirou, el antagonista del relato, quien, a través del ave, espía las acciones de Subaru (su contrincante y protagonista) y de su próxima víctima, una mujer líder de una secta religiosa de la New Age.

En las páginas descritas arriba se observa la representación de un pensamiento urbano en donde la ciudad actúa como mediación entre el mundo mágico y lo profano, lo moderno y lo antiguo; una representación en la que lo mágico navega entre la cotidianeidad y la mercadotecnia. Lo anterior se observa porque tanto Subaru como Seishirou, los dos protagonistas de Tokyo Babylon, son onmyouji, es decir, maestros del Onmyōdō, que es una de las formas que adoptó el taoísmo chino cuando entró a Japón (Siglos V y VI, periodo Yamato que va del III al VII), el cual

está basado en las viejas teorías del yin y el yang. Los practicantes de Onmyōdō utilizaban Yijing adivinación, purificaciones mágicas, y varios tipos de rituales para adivinar la fortuna o prevenir desastres. Como sea, el término Onmyōdō no puede encontrarse en China y Corea. Onmyōdō es una religión que vino a existir dentro de Japón. (Matsuo, 2013, p. 19)

En la imagen que analizamos, el halcón que se posa sobre el hombro de Sesihirou es un Shikigami;

los shikigamis son un tipo de espíritus divinos propios del folclore japonés. Se cree que los shikigamis se originaron del onmyōdō. Abe no Seimei es constantemente representado con uno o más shikigamis o espíritus sirvientes. Los hombres con grandes poderes espirituales pueden llamar la ayuda de espíritus para que les sirvan. (Taoist Sorcery, 2017)

La escena destaca debido a que el escenario en el que se encuentra parado Seishirou está en medio de la ciudad, con sus grandes rascacielos, la vista nocturna de las luces del tráfico y los espectaculares. Es la ciudad en la que Tokio se convirtió desde las décadas de los ochenta y principios de los noventa, época de la burbuja económica que permitió el crecimiento

sostenido por inversiones privadas excesivas en el mercado inmobiliario y la inflación de las acciones. Como resultado, los paisajes urbanos tradicionales se cambiaron en el centro de Tokio debido a la entrada de una enorme cantidad de dinero especulativo inyectado en el mercado inmobiliario que estimuló las tendencias generalizadas de desarrollo donde se demolieron viejos edificios y proliferaron pequeños lotes baldíos en espera de proyectos de redesarrollo posteriores. (Law et al., 2009, p. 33)

El Tokyo que se observa en este manga es aquel que, desde la década de los noventa, experimentó un auge en la actividad de construcción en el centro de la ciudad (Law et al., 2009), por lo que se destacan los fraccionamientos y apartamentos, los grandes rascacielos y edificios, la tecnología y las vías de circulación. En el propio manga se hace referencia al crecimiento acelerado de la industria de la construcción, en este caso, de

\footnotetext{
${ }^{5}$ Véase http://fanfox.net/manga/tokyo_babylon/v04/c001/22.html, o en su defecto http://www.mangahere.cc/manga/tokyo_babylon/v04/c001/22.html
} 
casas habitaciones, el consecuente encarecimiento de estas y la imposibilidad acceder a una por la deuda tan grande que se adquiere (CLAMP, 2016).

Sin embargo, representar una ciudad moderna y renovada (aún con las problemáticas que entraña) no exime a este manga de las representaciones de lo mágico y de la convergencia del espacio sagrado con lo profano. La imagen anteriormente descrita presenta ese espacio urbano en donde Seishirou, vestido con traje negro, corbata y saco, realiza un acto vinculado a la magia antigua japonesa y al onmyōdō, Esta escena condensaría, además lo que para Henry D. Smith es la ciudad como mediación, una de las actitudes antiguas que perviven en el pensamiento urbano japonés y que para Smith forma el basso ostinato ${ }^{6}$ de dicho pensamiento urbano (1978, p. 47). La ciudad como mediación se refiere a que no existe un contraste esencial entre la tierra de los dioses y la de los mortales, así que no hay tensión entre la capital real y una forma celestial (Smith, 1978, p. 47).

El espacio japonés está permeado por un pensamiento que no polariza. Aquí nos encontramos con el Ma y la horizontalidad, la cual, como dijimos en páginas anteriores, "funciona contra la verticalidad o dualismo occidental" (García, 1998, p. 44). En este sentido, se entiende que, a diferencia del pensamiento occidental en donde el ámbito de lo sagrado y lo profano están claramente diferenciados y se oponen, en Japón no hay una clara separación, por lo tanto, ambos aspectos se superponen.

Otra muestra de lo anterior se observa en el volumen número dos de la edición mexicana. En esta escena, Subaru habla con una mujer cuya hija fue asesinada tiempo atrás y que quiere vengarse. Ella asesina al perro de la niña muerta con el objetivo de crear un inugami o perro espiritual. Ella dice,

Mujer: Un inugami se invoca cortándole la cabeza a un perro querido y enterrándola. En realidad, tenía que enterrarla en un lugar donde pasara la gente, pero... aquí en Tokyo casi no hay lugares para enterrar un cadáver. Por eso decidí hacerlo en el templo Yasukuni. ${ }^{7}$ Cuando el perro muerto se convierta en inugami, seré su ama y hará lo que yo le ordene. (CLAMP, 2016, p. 35)

Según la tradición, los inugami son perros espirituales; se cree que el guardián del inugami podría enviarlo a atacar a aquellos contra los que tiene rencores (Farchild, 1962). En este diálogo no solo se resalta la pervivencia de rituales mágicos en el Tokyo moderno, sino que sitúa el proceso de creación del perro espiritual dentro de un espacio tradicional: el santuario sintoísta Yasukuni. En este capítulo de la historia, el dolor e impotencia de la mujer por no poder ver a su hija vengada por los medios legales, la hacen recurrir al pensamiento mágico como forma de huida de la realidad, una solución inmediata, "mágica": la búsqueda de venganza de una manera en la que no pueda ser culpada ni juzgada.

Esta idea de la ciudad como mediación incluye toda una serie de elementos vinculados al pensamiento mágico religioso antiguo que no polariza. Esos elementos son una de las constantes más marcadas en la gráfica y narrativa de Tokyo babylon, en donde observamos la tendencia a no contraponer el espacio urbano y el natural, sino a mezclarlos, debido a que

\footnotetext{
${ }^{6}$ Ostinato "es una técnica de composición consistente en una sucesión de compases con una secuencia de notas de las que una o varias se repiten exactamente en cada compás. De ahí su nombre en italiano, que significa 'obstinamento, empeño en repetir lo mismo"' (Schnapper, 2001). Se refiere a que es una constante y la base del pensamiento urbano japonés.

7 Templo shintoísta establecido en Kudan, Tokyo. Se fundó en 1869 (Yasukuni Shrine, 2008).
} 
este último, por lo general, se representa relacionado con la magia: en múltiples escenas, sin importar si los personajes se encuentran en la ciudad o dentro de un edificio, lo mágico trae consigo un cambio de dimensión en el que lo natural se superpone al escenario urbano.

El volumen dos de la edición mexicana nos muestra una de muchas representaciones de este tema. Se trata de una escena que abarca dos páginas: hay una sola viñeta en la parte superior derecha de la página derecha, y en ella se observa la mano enguantada de Subaru, empujando una puerta. La escena completa muestra, en picada, el interior de la estancia: Subaru abre ambas hojas de la puerta y desde ese ángulo se alcanzan a ver las sombras de las ventanas del hospital en el que se encuentran los personajes; pero en el interior de la estancia no hay más que vacío y pétalos de árbol de cerezo. En páginas más adelante observamos el propio árbol, que es lo único que se halla en dicha estancia ${ }^{8}$.

En la escena descrita en el párrafo anterior se destacan diferentes aspectos de un mismo pensamiento: el continuum entre lo natural y lo humano, lo mágico y lo profano. La naturaleza remite a la dimensión mágica, la simboliza, es lo que sucede con el árbol de sakura, el cual, dentro de la tradición oriental, es uno de los numerosos elementos que remiten, en el sureste de Asia, al inframundo, por su relación con la muerte (Klaus, 1982). Esta tendencia que no separa lo natural de lo urbano tiene una estrecha relación con el sentido indígena de un continuum del hombre y la naturaleza, pues "no existe un muro que provea de ninguna separación real o simbólica entre el hombre y la naturaleza" (Smith, 1978), y se enfatiza en la idea de que lo mágico y lo profano son aspectos que se superponen en este manga.

La ciudad como proceso es la segunda actitud en relación con la ciudad, derivada del pensamiento mágico religioso antiguo japonés (Smith, 1978), que se presenta en Tokyo Babylon de manera menos evidente, pero que rige la historia. Esta concepción se aprecia desde el nombre y las primeras páginas del volumen uno, con la analogía que se hace de la ciudad con Babilonia; de hecho, en el primer capítulo del volumen uno menciona a Babilonia de manera directa. ${ }^{9}$ La imagen es una página completa. En primer plano se observa la figura de Subaru a la mitad de la página: recostado de perfil, con la mano izquierda sobre el hombro derecho y la mano derecha en dirección al hombro izquierdo. Solo se aprecia su perfil y parte de sus hombros. Está vestido con una sudadera negra de cuello alto. Trae guantes. La cabeza y la espalda de Subaru son sostenidos por dos manos, de las cuales solo se aprecia la camisa que sobresale del saco negro. En la parte inferior izquierda sobresale la siguiente leyenda:

Babilonia, una antigua ciudad en Mesopotamia.

Fue establecida en el reino de Babilonia por el rey Hammurabi en el siglo VIII A.C y prosperó para convertirse en el centro político y cultural de oriente. Sin embargo, la gente se envaneció en su prosperidad y creyéndose dioses edificaron una torre que llegaba hasta el cielo y la nombraron 'Babel'. El Dios absoluto no les perdonó tal pecado e hizo descender su castigo sobre aquellos en la torre. El lenguaje en común que compartían desapareció. Los humanos siempre serán humanos, la insensatez que demostraron en aquella ocasión es prueba de ello.

Babilonia, la ciudad en catástrofe. La ciudad abatida por la ira de Dios (CLAMP, 2016, p. 46)

\footnotetext{
${ }^{8}$ Véase http://fanfox.net/manga/tokyo_babylon/v06/c000/81.html, o en su defecto http://www.mangahere.cc/manga/tokyo_babylon/v06/c000/81.html

${ }^{9}$ Véase http://fanfox.net/manga/tokyo_babylon/v01/c002/2.html, o en su defecto http://www.mangahere.cc/manga/tokyo_babylon/v01/c002/2.html
} 
La mención directa de Babilonia y la analogía con Tokyo se refuerzan desde las primeras páginas del tomo uno, en las que aparece la torre de Tokyo en picada, durante la noche, con las palabras “¿Odias la ciudad de Tokyo? Tokyo Babylon” y la posterior referencia a esta ciudad como aquella que nunca duerme (CLAMP, 2016, p. 7). De modo que se hace un vínculo directo entre Babilonia y Tokyo como capitales y ciudades de amplia civilización y riqueza; en el caso de la primera, dentro del judeocristianismo se representa como una ciudad en decadencia castigada por la ira de Dios.

Tokyo encarna también un proceso de decadencia, descomposición y corrupción; sin embargo, a diferencia de la idea judeocristiana del castigo divino que destruye de una vez por todas aquella ciudad pecadora, la representación que se hace de Tokyo en este manga, está ligada a la idea de la ciudad como proceso, la cual se encuentra entretejida por dos principales pensamientos: el concepto sintoísta de renovación cíclica y la transitoriedad o temporalidad budista (Smith, 1978), que hace que las representaciones de decadencia y corrupción sean presentadas como un proceso de renovación cíclica y continua. Al respecto, se dice que “...La idea de la renovación cíclica encontró expresión concreta en los festivales (matsuri) que se celebraban en la ciudad tradicional en un patrón que permanecía en armonía con las estaciones agrícolas" (Smith, 1978, p. 48).

Para Tetsuko Watsuji (citado por Matsui, 2014), el fudo (clima), término que "abarca el clima, los fenómenos meteorológicos, la geología, los accidentes geográficos y el paisaje de una región" (Matsui, 2014, p. 18), se relaciona con la manera como una cultura construye su concepción divina y religiosa. La vida en los bosques es cíclica. Al ser Japón una zona boscosa, las personas aprendieron a conocer el ciclo de vida de las plantas: crecimiento, descomposición, retorno a la tierra, emergencia de brotes y nuevo crecimiento (Matsui, 2014, p. 19). Lo anterior explica la importancia dada dentro de Tokyo Babylon al renacimiento; además del énfasis de la naturaleza como un aspecto vinculado de manera directa con lo mágico y lo sagrado.

El hecho de que lo cíclico y natural sea tan importantes dentro del sintoísmo, explica por qué el budismo, al entrar a Japón con el Vehículo Mayor del mahayana, pudo adaptarse tan bien a dicha religión indígena. Al igual que el sintoísmo, una de sus nociones básicas, samsara, "se originó en los bosques donde las altas temperaturas y la humedad ayudaron al rápido crecimiento de la vegetación" (Matsui, 2014, p. 19). El taoísmo, el budismo y el confucianismo entraron a Japón vía Corea durante los siglos V y VI, que corresponden al periodo Yamato (siglo III al VII). Durante este tiempo, la guerra entre Corea y China causaron que un buen número de inmigrantes llegaran a las islas japonesas. Así fueron introducidas diferentes artes auxiliares del gobierno, como la astrología, el calendario, las adivinaciones, y los mitos y las crónicas (Tanaka, 2011, pp. 48-52).

La cultura japonesa tiene una estructura múltiple. Se encuentra influida por diversas manifestaciones las cuales hibrida e integra a su cultura. Los samurai no fueron la excepción y desarrollaron un pensamiento marcado por el budismo zen:

para 1590, cuando Ieyasu Tokugawa se traslada a Edo, la aristocracia samurai poseía una cultura propia, desarrollada básicamente a partir de los modelos del periodo Muromachi (1333-1573) y consolidados en el periodo Momoyama (15731614) con el propósito de darle al shogunato una representatividad cultural. Durante el Muromachi se concretó el patronazgo de las artes por parte de la aristocracia 
samurai: los militares se adscribieron a la cultura generada por el budismo zen, la cual comportaba una austeridad muy compatible con el bushido o código samurai. (García, 1998, p. 27)

Durante este periodo (Edo), las clases sociales tuvieron una división muy clara: la élite, compuesta por el gobierno central (Bakufu), el provincial (daimyô) y la élite samurái; después seguían las órdenes religiosas budistas y, tras ellas, la clase plebeya (heimin). "Esta última, la más numerosa, se dividía por orden de importancia en agricultores, artesanos, comerciantes y proscritos o marginados (actores de kabuki, geisha, taikomochi, cantantes, ladrones)" (Rodríguez, 2017).

Durante el periodo Edo, florecieron dos miradas sobre la ciudad: la primera correspondía a la élite samurái, creada a partir de la política de separación de los samurái del campo (heinō bunri), "forjada con la intención de romper los vínculos entre los samurái y los campesinos y así disminuir el peligro de una amenaza a los intereses de gobierno" (García, 2005, p. 14). El pensamiento urbano samurái tuvo dos vertientes opuestas: la primera estaba basada en "una política pro urbana estancada, para mantener a la clase militar aislada en las ciudades, consecuentemente alentaba permanente cambio a través del crecimiento del comercio, dinero y consumo" (Smith, 1978, p. 49). La segunda era una "política anti urbana estancada en la necesidad política de resistir cualquier cambio desestabilizador en el conjunto de la estructura socio económica. Esta tensión dio lugar en el siglo XVIII a un debate sobre la práctica pro-urbana contra la ideología agraria" (Smith, 1978, p. 49). Esta oposición generó dos nociones diferentes de ciudad dentro del pensamiento samurai: la ciudad como poder y la ciudad como corrupción y cambio, las cuales están presentes en la gráfica y narrativa de Tokyo Babylon.

La ciudad como poder está presente al hacerse la analogía con Babilonia como un centro de poder y civilización. La idea se acentúa con la representación gráfica de la ciudad: los grandes rascacielos, las vías de circulación, las luces nocturnas que corresponden con el periodo de desarrollo urbano y la burbuja económica de Japón, la cual, para el momento de creación de este manga, aún estaba en auge. Por otro lado, la misma analogía con Babilonia nos lleva a la noción de la ciudad como corrupción y cambio, y los casos que se van desglosando dentro de la historia nos lo confirman: una ciudad que teme a la otredad, que nunca integra a los extranjeros, ni a los discapacitados, y discrimina a los ancianos; una ciudad en donde es un lugar común la traición y el engaño. De hecho, esta noción de ciudad es ambivalente: por un lado, destaca los horrores, discriminación, asesinatos, etc. Todos esos hechos son realizados por las personas de Tokyo, quienes van a personificar la ciudad. El mismo Seishirou le dice a Subaru en el último volumen:

Seishirou: ¿Sientes que te he traicionado? Aquí en Tokio eso es cosa de todos los días. Traición de un humano a otro. Ese tipo de cosas... Aquí en Tokyo es muy común. (CLAMP, 2016, pp. 209-2011)

Tokyo se representa como una ciudad corrupta en la que se traiciona, asesina, viola, golpea, y se entrelaza con la idea de la ciudad como proceso, derivada del pensamiento budista: este Tokyo pasa un proceso de corrupción. No debemos olvidar que este manga se encadena temporal y espacialmente con $X$ (Ekkusu), otro manga de las mismas autoras, en el cual la ciudad de Tokyo va a encontrar su fin en 1999, de la mano de los siete ángeles o dragones de la tierra que detonan el apocalipsis. 
Sin embargo, no todo es corrupción en la ciudad que se representa en Tokyo Babylon. En este manga, como hemos visto, confluyen diversos aspectos derivados de distintas concepciones religiosas que se integraron a la tradición japonesa. Ya habíamos hablado del Onmyōdō cuando explicamos que Subaru y Seishourou representaban ese tipo de magia, recordábamos que el Onmyōdō estaba basado en la doctrina de opuestos complementarios del yin yang taoísta que entró a Japón junto con el budismo y el confucianismo. Pues bien, toda la historia de Tokyo Babylon está creada a partir de ese ciclo de opuestos complementarios que son el yin y el yang. Sus protagonistas son una clara muestra de ello en tanto que Subaru representa al Yang o principio luminoso, masculino y Seishirou al Yin o principio oscuro. Para el taoísmo, "el mundo representa una totalidad de orden cíclico (Tao), constituida por la conjugación de dos manifestaciones alternantes y complementarias" (Eliade, 1999, p. 34). Lo anterior implica que dichas manifestaciones son en realidad uno mismo. No se trata de elementos irreconciliables y contrapuestos, sino de opuestos vinculados y pertenecientes a una totalidad. Si Tokyo se representa como corrupción, también se destacan aspectos positivos en donde la misma gente que corrompe la ciudad, lucha y se esfuerza por ser mejor. Otro diálogo de Seishirou nos lo confirma:

Seishirou: Me parece que están equivocadas. Lo extraordinario de este mundo son aquellas personas que con los pies en la tierra se esfuerzan cada día viviendo una vida normal. Cada mañana se levantan temprano, cada día van a la escuela, cada día trabajan... lloran, ríen, se preocupan y sufren, viven en realidad con todas sus fuerzas... ustedes se ríen de ellos. Pero ¿no creen que serían más felices viviendo como ellos? (CLAMP, 2016, pp. 410-411)

Así pues, observamos en este manga la noción de la ciudad como proceso, como poder, como corrupción, la cual se encamina a su destrucción para entrar con posterioridad a un momento de renovación. La tabla 1 condensa los resultados de lo ya expuesto antes:

Tabla 1. Dos concepciones del espacio urbano: visión racional occidental y visión mágica oriental

\begin{tabular}{|l|l|}
\hline Pensamiento urbano occidental & Pensamiento mágico oriental urbano \\
\hline Visión dualista ciudad y hombre & Visión monista ciudad y hombre \\
\hline Contraste naturaleza y ciudad & Continuo naturaleza y ciudad \\
\hline Verticalidad urbana & Horizontalidad urbana \\
\hline Distinción entre lo sagrado y profano & $\begin{array}{l}\text { Sentido indistinto entre lo sagrado y lo } \\
\text { profano }\end{array}$ \\
\hline $\begin{array}{l}\text { Existe una frontera entre lo mágico y lo } \\
\text { humano }\end{array}$ & $\begin{array}{l}\text { No existe frontera entre lo mágico y lo } \\
\text { humano }\end{array}$ \\
\hline $\begin{array}{l}\text { Ciudad como algo impersonal y con } \\
\text { resultado definido }\end{array}$ & $\begin{array}{l}\text { Ciudad como agente mediador y como } \\
\text { proceso }\end{array}$ \\
\hline $\begin{array}{l}\text { Justicia urbana siempre en manos de los } \\
\text { hombres }\end{array}$ & $\begin{array}{l}\text { Justicia urbana en ocasiones en manos de } \\
\text { lo mágico }\end{array}$ \\
\hline $\begin{array}{l}\text { Espacio urbano sujeto a la ley física de la } \\
\text { energía entrópica de destrucción }\end{array}$ & $\begin{array}{l}\text { Espacios urbanos sujetos al concepto } \\
\text { sintoísta de la renovación cíclica y el } \\
\text { renacimiento }\end{array}$ \\
\hline La ciudad es poder económico y político & $\begin{array}{l}\text { La ciudad es poder gobernado por } \\
\text { fuerzas de ying y yang }\end{array}$ \\
\hline
\end{tabular}

Fuente: Elaboración propia 


\section{Discusión}

Los estudios que analizan la manera en la que persiste la magia en los entornos urbanos son escasos y se alejan de la manera en la que analizamos esta fuente. En la revisión realizada encontramos dos vertientes: en la primera encontramos estudios que en su mayoría son de corte antropológico, sobre la persistencia de prácticas mágicas en determinados espacios; a la segunda se inscriben los análisis de corte teórico-reflexivo que examinan la persistencia de la magia y los mitos en la sociedad contemporánea y moderna. A la primera vertiente pertenece el estudio de Carlos Alberto Uribe, quien realiza un análisis sobre la manera en la que el conflicto social y la violencia en Colombia ofrecen un generoso caldo de cultivo para la práctica de la brujería, aspecto que analiza con el estudio de caso de una familia antioqueña (2003). En este artículo, las prácticas mágicas se entrelazan con las acciones cotidianas de la familia estudiada, en un contexto de violencia general. En cambio, en la segunda vertiente encontramos a Carlos Alberto Carretero Pasín (2006), quien analiza la manera en la que los imaginarios y los mitos mantienen continuidad y se mezclan con las formas más representativas de la modernidad. Carretero centra su análisis en la forma como la sociedad contemporánea traslada la magia e idealización de esta al ámbito político. "De igual modo, las utopías políticas reactualizan un antiguo mito mesiánico que aspira a la consecución de un paraíso terrenal en el que se alcance un estado de pureza absoluta; un orden social ideal, nunca realizado y proyectado en el porvenir" (Carretero Pasín, 2016, p.121). Esta serie de estudios se inscriben en una larga literatura que valora la persistencia y la mezcla del aspecto mágico religioso en la modernidad; sin embargo, no se centran de manera específica en su manifestación urbana. En relación con los estudios que analizan la manera en la que persisten la representación mágica en el entorno urbano representado en el manga y el anime, encontramos solamente estudios que se centran en la representación de la magia y la religión en dichos productos de la industria cultural japonesa. Estos se dividen en dos enfoques: los que estudian el contenido y los que se van por la audiencia. Los de la primera vertiente son abundantes, y tenemos aquí a Álvaro Acevedo Merlano (2020), quien analiza tres animes japoneses diferentes a los que propone como formas de arte expresivo, a través de los cuales se pueden analizar las tensiones entre las prácticas ancestrales y la tecnociencia. En esta misma línea encontramos el estudio de Isuki Castelli (2018), quien analiza la manera en la que los elementos de la New Age se presentan mezclados con el judeocristianismo, el budismo y el shinto, en otro manga de CLAMP intitulado $X$ (Ekkusu). Aquí encontramos también los estudios que analizan la presentación folclórica, mágico religiosa en los diversos casos de estudio, particularmente en el anime y no en el manga. Tal es el caso de Okuyama (2015) y Foster (2016).

Un segundo enfoque que analiza las representaciones mágico-religiosas en el manga y el anime se enfoca en la importancia de estos aspectos como elementos difusores de la cultura religiosa japonesa ante las audiencias de distintas partes del mundo. Esta lista es más larga, pues aquí encontramos también los estudios de las audiencias de OgiharaSchuck (2014) y Baraka Thomas (2012). Sin embargo, en ninguna de las líneas analizadas con anterioridad se estudia específicamente la manifestación de la magia en el entorno urbano representado en el manga y el anime; sobre todo si analizamos que la perspectiva de la cultura japonesa no polariza, sino que sus opuestos se mezclan en un solo punto, lo que hace que la representación de lo imaginario y mítico en el entorno tecnológico de Tokyo sea muy particular.

El estudio que realizamos tiene en común con los análisis examinados en los párrafos que se trata de examinar la manera como las continuidades del pensamiento y las prácticas 
humanas, vinculadas a la magia, se manifiestan en un ámbito humano, el urbano, en este caso. Pese a que no se encontraron otros trabajos que aborden este tema en específico, sí son importantes los avances que ahondan en la manera en la que el factor imaginario manifiesta continuidad, rupturas o mezclas en las diversas manifestaciones de la sociedad contemporánea.

\section{Continuidades y discontinuidades}

Hablando de continuidades y rupturas del pensamiento mágico en las manifestaciones humanas, tenemos que, para Lefebvre (1978), el pensamiento urbano tiene una serie de continuidades y discontinuidades, lo que nos permite entender por qué hay ciertos aspectos que permanecen dentro de lo urbano y por qué hay elementos que aparecen de manera efímera. Una de las continuidades más marcadas que observamos en Tokyo Babylon es la del pensamiento mágico-religioso que impregna cada una de las esferas de la vida japonesa representada: observamos reminiscencias del sintoísmo con sus planteamientos sobre renovación, el budismo que marcaría al bushido samurái, el Onmyōdō basado en la doctrina taoísta del bien y el mal; aspectos mágicos que se encuentran en la base del pensamiento en torno a la ciudad y que orientan a pensarla como un mediador, un proceso, como poder o decadencia. Para Lefebvre (1978),

la ciudad y lo urbano no pueden comprenderse sin las instituciones salidas de las relaciones de clase y de propiedad. La ciudad, a su vez, obra y acto perpetuos, da lugar a instituciones específicas: municipales (...) En ella, coexisten las instituciones propiamente urbanas, administrativas y culturales. De ahí algunas continuidades notables a través de los cambios de la ciudad (..) Las discontinuidades no se sitúan únicamente entre las formaciones urbanas, sino también entre las relaciones sociales más generales, entre las relaciones inmediatas de los individuos y los grupos. (pp. 71-72)

Nuestra primera continuidad es la religión y lo mágico, pero todas las concepciones anteriormente mencionadas están marcadas por lo político. La ciudad como proceso implica un sintoísmo que tuvo la necesidad de autodefinirse cuando el budismo y otras religiones llegaron a Japón de la mano de los migrantes. El sintoísmo estuvo largamente interrelacionado con la política japonesa porque era el sistema que le daba un carácter divino al emperador. El budismo no se quedó atrás y jugó un papel importante no solo para la cultura samurái, sino para la cultura chônin, la cual salió de Japón cuando este abrió sus fronteras en el siglo XIX. Si nos acercamos más al presente, la misma ciudad de Tokyo que se representa corresponde a aquella que cumplía con las políticas económicas mundiales de la época: el modelo neoliberal que empezó a implantarse en las décadas de los ochenta y noventa. Smith (1978) expresa que, para entender el pensamiento en torno a la ciudad y lo urbano en Japón, hay que tomar en cuenta tanto lo religioso como lo político, debido a la estrecha relación entre ambos.

Lo anteriormente expresado no significa que lo que planteamos como continuidades sean eternas e inalterables, sino que han mutado a través del tiempo: se adaptan a los hechos y a las discontinuidades. "En el tiempo y en el espacio, suceden disoluciones de estructuras y reestructuraciones, siempre traslúcidas sobre el terreno, inscritas en lo práctico sensible, escritas en el texto urbano, pero derivando de una procedencia distinta: la de la historia del devenir" (Lefebvre, 1978, p. 73). Tal es la manera en la que se observa la persistencia de la magia en la representación que se hace de ella en Tokyo Babylon y, en este sentido, nuestro estudio confluye con los estudios examinados en líneas arriba, en donde el análisis 
de los factores religiosos persistentes en objetos, prácticas y procesos sociales contemporáneos se examina como algo fluido, en cambio y movimiento, en donde lo mágico se mezcla, hibrida y reestructura a lo largo de diversos procesos temporales.

\section{La magia como escape a la opresión social}

En páginas anteriores citamos a Bourdieu (2012) cuando afirmaba que "la Magia [es] el mismo carácter colectivo de la religión" (p. 17), y es precisamente lo que se observa en Tokyo Babylon: la supervivencia de ese carácter mágico-religioso representado sin polarización en la ciudad moderna de Tokyo. En efecto, como estudiamos en páginas anteriores, en Japón, la dinámica filosófica y religiosa da paso a un pensamiento que no opone ni polariza, y que se observa en la fuente analizada, en donde los personajes acceden a soluciones mágicas de manera muy cotidiana, porque ese factor está al alcance de su cotidianeidad y forma parte de su mundo. Sin embargo, hay que decir en este apartado que, si bien la magia es algo común en el pensamiento y construcción de la ciudad de Tokyo en Tokyo Babylon, los personajes sí acuden a ella en condiciones específicas: cuando, en efecto, sus problemas no pueden resolverse con la intervención de las autoridades o instituciones del ámbito político o jurídico. Tal es el caso de la imagen analizada arriba, en donde la madre de una niña asesinada decide realizar un ritual para crear un inugami que logre su venganza. De hecho, toda la ciudad es representada como el pecado y la perdición, lo que genera que sus habitantes recurran al protagonista en busca de esas soluciones mágicas que tienen a la mano, porque las respuestas de lo instituido en el ámbito profano han dejado de ser eficaces.

Algo similar ocurre con la manera en la que se representa a la ciudad: como un actante y un ser más que se mueve a la par de sus habitantes. En este manga, la ciudad de Tokyo representa el lugar del éxito, de las ilusiones, la tecnología y de la mejora de muchos de sus habitantes, con cuyas historias se topa el protagonista y todos ellos terminan desilusionados y muertos. En Tokyo Babylon la ciudad está viva y mantiene características humanas porque está fetichizada: sus personajes no la ven como un sistema de relaciones sociales sino como una cosa viva que eleva o destruye a voluntad (González, 2014), y es por esto que el eje rector de la historia tiene que ver con los personajes que han tenido pérdidas debido a esta noción elevada de la ciudad que no cumple con sus expectativas y los hiere. La resolución de estos casos siempre enfatiza el carácter dual: ahí donde hay corrupción hay bondad, ahí donde se vislumbra a la ciudad de Tokyo como un colectivo viviente, se destaca a los individuos que la conforman, en un ciclo interdependiente en donde nada es solo blanco y negro, sino que tiene matices y gradaciones intermedias. Es una representación muy rica y compleja de Tokyo.

\section{Conclusiones}

En este artículo tuvimos como objetivo analizar la manera en la que la magia muestra persistencia en los productos culturales de un país altamente tecnologizado como Japón, el cual, sin embargo, sigue su propia cosmovisión que no necesariamente opone la noción de la magia a la de modernidad. En Tokyo Babylon observamos la persistencia de diversas nociones de ciudad, que se gestaron y tuvieron su auge a lo largo de la historia de dicho país, y que la conciben como un mediador en donde la magia se manifiesta en cada acción cotidiana; y, por otro lado, como proceso de descomposición en donde la ciudad de Tokyo, en la cúspide del poder, se presenta caminando a la decadencia.

Dice Sánchez Vázquez (1975) que la utopía o las distopías existen porque son compensaciones a las limitaciones del presente. $\mathrm{Y}$ tal vez algo parecido pueda decirse de 
la magia y de su versión actual como fenómeno social: pervive porque aún las condiciones presentes no han formulado respuestas más transparentes. El discurso de la modernidad fue en esencia un discurso político que tenía como propósito hacer ver a las sociedades precedentes como acientíficas y en cierta medida como irracionales. Así, descartó de sus referentes los elementos relacionados con el pensamiento mágico, aspecto que por una $\mathrm{u}$ otra razón ha pervivido, con muchas metamorfosis, desde tiempos primigenios hasta la fecha. Sin embargo, aún hay elementos de la vida urbana que convocan y reproducen el pensamiento mágico: el miedo a la otredad, la sobrevivencia ante hechos incontrolables y de aparición cíclica de la naturaleza, el encontrarle sentido y significado profundo a los espacios o el entender a la ciudad como un sujeto automático que controla y dirige el devenir.

En Tokyo Babylon, si bien la magia es una forma de resistencia de los habitantes de Tokyo para salir de sus problemas y sobrevivir, no encubre ninguna problemática social porque converge con ellas, se les integra, forma parte de ellas... se representa como algo que converge con los aspectos más duros de la modernidad y de la ciencia. La magia sí existe y se traslapa con lo profano; por lo tanto, se representa una sociedad en la que sí hay soluciones que pueden ser inmediatas y más eficaces que los procesos racionales de la modernidad. Soluciones que viven y convergen con la modernidad.

La razón de tal representación y de tal mezcla de mundos corresponde con la cultura que dio a luz a este manga: la sociedad japonesa adaptó los elementos importados de cómic occidental a su modo de ver el mundo, el cual, vinculado con la religión y la filosofía taoísta, no polariza, sino que integra los aspectos que en occidente se podrían considerar opuestos, como lo sagrado y lo profano. El ir y venir del mito, su reelaboración y reemergencia son una constante en el sujeto y en la sociedad humana. La japonesa no es la excepción, aunque su propia filosofía importada de los chinos les hace no polarizar, por lo que la presencia y la convergencia de lo mágico parece más permanente en sus representaciones como el manga.

Aunado a lo anterior, nos encontramos ante un renacer del mito. Gilbert Durand (2003) sostiene que, aunque lo imaginario, la magia y los mitos existen siempre bajo continuas reelaboraciones contextuales y culturales, "existen explosiones, precipitados míticos como el que vivimos en la actualidad" (p. 39).

En Tokyo Babylon, las autoras plasmaron sus inconformidades e inquietudes de juventud: "así que se nos ocurrió tratar temas más sociales. Por aquel entonces éramos más jóvenes y había muchos aspectos de la sociedad contra los que nos queríamos rebelar" (CLAMP, 2004, p. 5). Debido a lo anterior, en Tokyo Babylon la magia brinda la posibilidad de obtener soluciones rápidas a las problemáticas sociales, aparentemente más eficaces que las científicas, en las que por cuestiones de espacio no profundizamos aquí pero que están presentes en el manga y detonan las soluciones mágicas. En este manga se enfatizan los problemas de acceso a la ciudad, a los lugares a los que cualquier ciudadano tiene derecho, la discriminación, la violencia, la traición, la ineficacia de las autoridades. Se visibilizan las problemáticas de cualquier ciudad y sociedad humana, matizadas por la magia y los mitos, los cuales parecen dar a las personas ahí representadas una posibilidad y una esperanza latente. 


\section{Referencias}

Acevedo-Merlano, A. (2020). El animé como lienzo para analizar las tensiones entre prácticas epistémicas ancestrales y tecnocientíficas. Utopía y Praxis Latinoamericana, 89(25), 211-226.

Baraka, T. J. (2012). Drawing on tradition manga, anime and religion in contemporary Japan. Honolulu: University Hawai'i Press.

Bombara, P. y Valenzuela A. (2015). Ciencia y superhéroes: experimentos, hipótesis, héroes y vilanos ;Al infinito y más allá! México D.F: Siglo XXI editores.

Botton, F. (2003) Los juegos fantásticos. México: Facultad de filosofía y Letras-UNAM

Bourdieu, P. (2012). El costurero y su firma. En I. Jiménez, Pierre Bourdieu. Capital simbólico y magia social (págs. 17-85). México: Siglo XXI editores.

Carretero Pasín, E. Á. (2006). La persistencia del mito y de lo imaginario. Política y Sociedad, 43(2), 107-126.

Carmona, M. (2004). Implementing urban renaissance-problems, possibilities and plans in South East England. Progress Planning (56), 169-250.

Carrión, F. (2005). El centro histórico como proyecto y objeto de deseo. Eure, XXXI, (93), 89-100, Santiago de Chile.

Castelli Olvera, S. I. (2017). La noción del espacio en el manga Ekkusu (X): entre lo tradicional y la. Espacialidades, 7(2), 163-186.

Castelli Olvera, I (2018). Los elementos de la New Age en el manga X de CLAMP. Jangwa Pana, 17(1), 1-17. Doi: http://dx.doi.org/10.21676/16574923.2295.

Colón, C. y Flores, O. (coords.) (2018) Los otros y nuestros monstruos: acercamientos a la literatura fantástica. México: Universidad Autónoma Metropolitana Azcapotzalco.

Cortés, J. (2010). La ciudad cautiva control y vigilancia en el espacio urbano. Madrid: Akal.

Durand, G. (2003). Mitos y sociedades introducción a la mitodología. Buenos Aires: Biblos.

Eliade, M. (1999). Historia de las creencias y las ideas religiosas (Vol. II). Buenos Aires: Paidós.

Entrevista con CLAMP. (2004). Antología CLAMP, 3.

Farchild, W. P. (1962). Shamanism in Japan", Asian Ethnology, 21.

Foster, M. D. (2016). The folkloresque circle: Toward a Theory of fuzzy allusion. En M. D. Foster y J. A. Tolbert, The folkloresque: Reframing Folklore in a popular Culture World (pp. 47-75). Logan: Utah State University Press..

García Cárdenas (2010) El simbolismo del espacio en Tiempo destrozado. En O. Flores y G. Vergara, (coords.). Ocho escritores latinoamericanos del siglo XX. México: CONACyT-Universidad de Colima-UAM

García Montiel, E. (1998). Muerte y resurrección de Tokio. Arquitectura y urbanismo, 1868-1930. México: El Colegio de México.

García Rodríguez, A. (2005). Cultura popular y grabado en Japón siglos XVII al XIX. México: El Colegio de México.

Ginzburg, C. (1999). Mitos, emblemas e indicios, morfología e historia. Barcelona: Gedisa.

González, G. (2014). Circo sin pan. Regeneración y mercantilización en el centro histórico. México, D.F.: Universidad de Zacatecas y Miguel Ángel Porrúa.

Kindersley, D. (2015). El libro de la sociología. México: Altea.

Klaus, A. (1982). Death and transformation: the presentation of Death in East and Southeast Asia. Asian Folklore Studies, 41(2), 147-162. 
Law, C., Chan, J. C., Chui, E., Wong, Y., Lee, K., \& Chau, F. L. (2009). Study Report Urban Renewal Policies in Asian Cities for the Urban Renewal Strategy Review. University of Hong Kong.

Lefebvre, H. (1978). El derecho a la ciudad. Barcelona: Península.

Matsui, K. (2014). Geography of Religion in Japan Religious Space, Landscape, and Behavior. Tsukuba: Springer.

Matsuo, S. (2013). Chinese religión and the formation on Onmyoodo. Japanese Journal of Religious Studies, NanZan Institute of Religion and Cultures, 40(1).

Nieto, O. (2015) Teoría general de lo fantástico. Del fantástico clásico al posmoderno. México: Universidad Autónoma de la Ciudad de México.

Okuyama, Y. (2015). Japanese Mythology in film: a semiotic approach to reading japanese film and anime. Lanham: Lexington Books.

Ornelas, J. (2015). Lo urbano y la crítica de la economía política. En I. J. Castillo, Las zonas metropolitanas. Reflexiones teóricas y estudios en el centro del país (pp. 1744). Tlaxcala: Universidad de Tlaxcala y Miguel Ángel Porrúa.

Osorio, J. (2009). El megarrelato posmoderno. CyE 1(2), 141-155.

Pardo, J. (5 de enero de 2012). Zona negativa. Opinión y actualidad sobre el mundo del cómic y las galaxias cercanas. Recuperado el 28 de noviembre de 2017 de http://www.zonanegativa.com/tokyo-babylon/

Rodríguez, D. (24 de abril de 2017). Ecosdeasia. Recuperado de http://revistacultural.ecosdeasia.com/la-economia-del-periodo-tokugawa-crisiseconomicas-y-pensamiento-de-la-epoca/

Sánchez Vázquez, A. (1975). Del socialismo científico al socialismo utópico. México D.F.: Era.

Schnapper, L. (2001). New Grove Dictionary of Music and Musicians, ed. Stanley Sadie. Schnapper, Laure: «Ostinato». New Grove Dictionary of Music and Musicians. Schnapper, Laure: «Ostinato». New Grove Dictionary of Music and Musicians, ed. Stanley Sadie. Macmillan, 2001 [1980].

Smith, H. D. (1978). Tokyo as an a idea: An exploration of japanese urban thought until 1945. Journal of japanese Studies.

Tanaka, M. (2011). Historia mínima de Japón. México: El Colegio de México.

Taoist Sorcery. (29 de noviembre de 2017). Obtenido de http://taoistsorcery.blogspot.mx/2013/06/onmyodo-taoist-sorcery-in-ancient-japan.html

Tsukamoto, Y., Fujimura, R., \& Shiner, E. (2008). Typo-Morphology of Tokyo. Perspecta, 40, 32-41.

Uribe, C. A. (2003). Magia, brujería y violencia en Colombia. Revista de Estudios Sociales (15), 59-73.

Velasco, M. (2007) El cuento: la casa de lo fantástico. México: Fondo editorial tierra adentro.

$\begin{array}{lll}\text { Yasukuni Shrine } & \text { (2008). }\end{array}$ http://www.yasukuni.or.jp/english/about/index.html 